
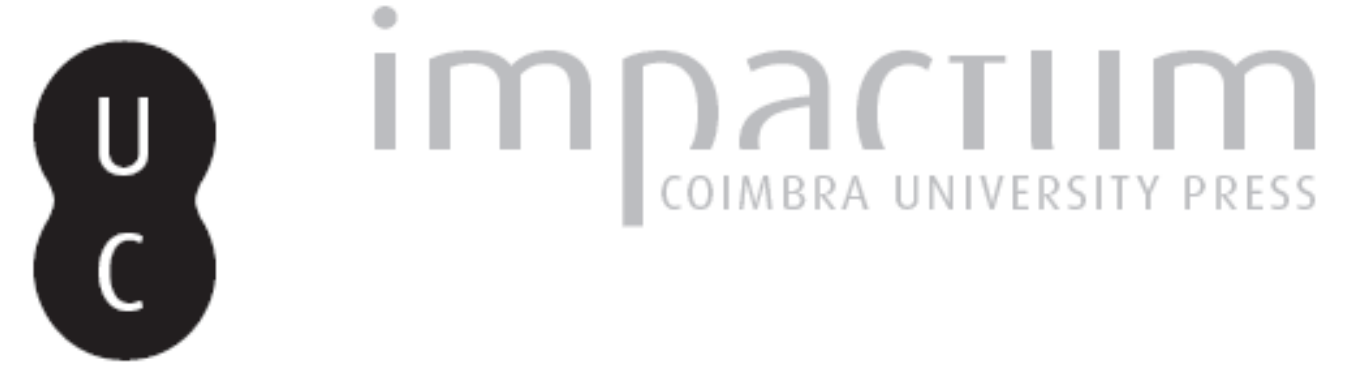

O edifício da Biblioteca Geral da Universidade de Coimbra (1936-1956)

Autor(es): $\quad$ Costa, João Pedro Cardoso Gomes da

Publicado por: Imprensa da Universidade de Coimbra

URL persistente:

URI:http://hdl.handle.net/10316.2/42750

DOI:

DOI:https://doi.org/10.14195/1647-8436_46_47_3

Accessed : $\quad$ 26-Apr-2023 09:44:05

A navegação consulta e descarregamento dos títulos inseridos nas Bibliotecas Digitais UC Digitalis, UC Pombalina e UC Impactum, pressupõem a aceitação plena e sem reservas dos Termos e Condições de Uso destas Bibliotecas Digitais, disponíveis em https://digitalis.uc.pt/pt-pt/termos.

Conforme exposto nos referidos Termos e Condições de Uso, o descarregamento de títulos de acesso restrito requer uma licença válida de autorização devendo o utilizador aceder ao(s) documento(s) a partir de um endereço de IP da instituição detentora da supramencionada licença.

Ao utilizador é apenas permitido o descarregamento para uso pessoal, pelo que o emprego do(s) título(s) descarregado(s) para outro fim, designadamente comercial, carece de autorização do respetivo autor ou editor da obra.

Na medida em que todas as obras da UC Digitalis se encontram protegidas pelo Código do Direito de Autor e Direitos Conexos e demais legislação aplicável, toda a cópia, parcial ou total, deste documento, nos casos em que é legalmente admitida, deverá conter ou fazer-se acompanhar por este aviso.

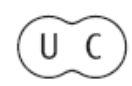




\section{BOLETIM DA \\ BIBLIOTECA GERAL DA UNIVERSIDADE DE COIMBRA}

VOL. 46/47 (2015/2016)

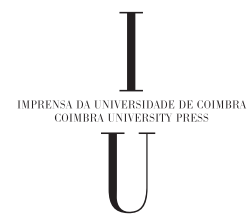




\title{
O edifício da Biblioteca Geral da Universidade de Coimbra (1936-1956)
}

\author{
João Pedro Cardoso Gomes da Costa ${ }^{1}$
}

\section{RESUMO}

Este texto foi escrito como um contributo para a monografia Os Livros em sua ordem. Coimbra: Imprensa da Universidade, 2014, comemorativo dos 500 anos da Biblioteca da Universidade de Coimbra, e cobre o período relativo à construção do novo edifício da Biblioteca Geral. Como foi muito adaptado para aquela edição, republica-se aqui na sua versão original.

\section{PALAVRAS-CHAVE}

Universidade de Coimbra. Biblioteca Geral, edifício;

Universidade de Coimbra. Biblioteca Geral, história.

\section{ABSTRACT}

This text was written as a contribution to the $500^{\text {th }}$ anniversary book Os Livros em sua ordem. Coimbra: Imprensa da Universidade, 2014, and covers the period of time relating to the construction of the new building of the General Library of the University of Coimbra. Since it was severely adapted for that purpose, it is now reprinted in its original version.

\section{KEYWORDS}

University of Coimbra. The General Library, building;

University of Coimbra. The General Library, history.

1 Aluno de Mestrado, Universidade de Coimbra 
Em 1934, e após uma solicitação do Senado da Universidade de Coimbra feita como resposta à recente decisão governamental da criação de uma cidade universitária em Lisboa, foi nomeada a primeira comissão de obras que ficou responsável por delinear o projeto geral da remodelação da Cidade Universitária de Coimbra. Em 1936, foi apresentado o relatório desta comissão onde pela primeira vez foi feita a proposta para a transformação do então edifício da Faculdade de Letras em Biblioteca Central, posteriormente designada por Biblioteca Geral da Universidade de Coimbra (Rosmaninho, 2002).

No entanto, o trabalho da primeira comissão depressa cairia no esquecimento e, em 1939, foi nomeada uma segunda comissão com o mesmo objetivo da primeira. A segunda Comissão de Obras considerou inicialmente que o edifício da Faculdade de Letras deveria manter a sua utilização, sendo que à Biblioteca Geral estaria destinado um edifício novo construído de raiz (Rosmaninho, 1996).

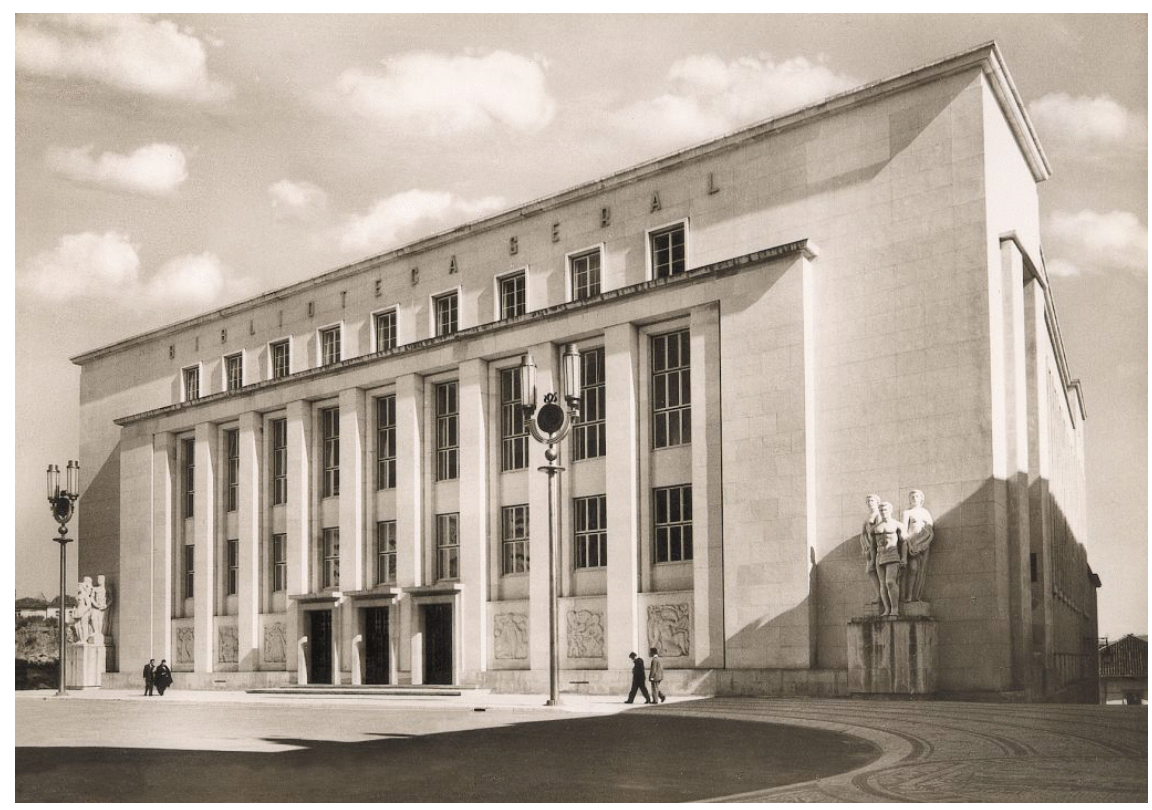

A Biblioteca Geral nos anos sessenta. 
Seria uma visita a Coimbra do Ministro das Obras Públicas, Duarte Pacheco, em 25 de fevereiro de 1940, a pôr um ponto final na questão. Foi recuperada a solução proposta pela Primeira Comissão de Obras da Cidade Universitária de Coimbra e o edifício da Faculdade de Letras tinha agora o aval definitivo para ser transformado em Biblioteca Geral da Universidade de Coimbra (Rosmaninho, 2002).

Em 1941, foi nomeada a Comissão Administrativa para as Obras da Cidade Universitária de Coimbra, ou CAPOCUC, que teria o papel de avançar com as intenções, projetar e realizar a remodelação da Cidade Universitária de Coimbra. Um ano depois, surgiu o primeiro ensaio de conjunto pela mão do arquiteto-chefe da CAPOCUC, Cottinelli Telmo, onde estava prevista a transformação do edifício da Faculdade de Letras em Biblioteca Geral.

A ideia de Cottinelli fica demonstrada numa carta que enviou posteriormente ao Ministro das Obras Públicas, quando refere que "a fachada principal deste edifício [Faculdade de Letras] - para falar só no pior - é considerada unanimemente má, pelo que será completamente demolida e substituída por outra, sóbria e condigna do aspeto arquitetónico que queremos imprimir à nova Cidade Universitária. (...) É preciso lembrarmo-nos que ele [o edifício] nasceu para "teatro dos estudantes" e que, melhor do que o foi para uma Faculdade de Letras, a sala de espetáculos foi, no atual projeto de biblioteca, aproveitada para uma grande sala de leitura" (citado por Rosmaninho, 2002:398).

Tomada a decisão a favor da remodelação, era preciso concretizar. E foi nesse sentido que, em 12 de março de 1942, o diretor da Biblioteca Geral, Damião Peres, apresentou o programa do que considerou os "Elementos essenciais para a futura instalação da Biblioteca Geral da Universidade de Coimbra". Deste programa fazem parte, para além de uma série de pontos dedicados a espaços públicos, de serviço, técnicos e administrativos, uma "sala de leitura geral com capacidade para trezentos leitores" e um depósito de revistas, jornais e livros, 
"com a capacidade total para 500 mil volumes". Estes dois pontos tornam percetível a escala do que se pretendia. Seis meses depois foi apresentada a proposta da CAPOCUC, sobre a forma de anteprojeto, cuja elaboração "foi orientada no sentido de satisfazer o programa e não ultrapassar a verba prevista para a obra", que mereceria, mais tarde, a aprovação "sem reparos" do diretor da Biblioteca Geral (AUC, CUC 2010-267).

Depois das necessárias alterações feitas ao anteprojeto, o projeto foi submetido à aprovação do Ministério das Obras Públicas em 5 de junho de 1944 (AUC, CUC 2009-163).

Alberto Pessoa foi o arquiteto escolhido para desenvolver o projeto da transformação do edifício, ainda que "estritamente dirigido por Cottinelli" (Rosmaninho, 2002:682). Diplomado em 1943, já desde o ano anterior colaborava na Comissão Administrativa do Plano de Obras da Praça do Império e da Zona de Belém, em Lisboa, da qual Cottinelli era o arquiteto-chefe. Esta terá sido, provavelmente, a razão de acompanhar Cottinelli no caminho para a CAPOCUC. Além do projeto de arquitetura, foi o autor do projeto do mobiliário para a Biblioteca Geral e fez a inspeção das obras durante a sua execução (AUC, CUC 2010-267).

Em 16 de junho de 1944, o projeto para adaptação do edifício da Faculdade de Letras a Biblioteca Geral foi aprovado por despacho do Ministro da Obras Públicas. Pela memória descritiva entende-se que pouco foi modificado relativamente ao anteprojeto apresentado em 1942. Este projeto previa uma área total de construção de $8878,51 \mathrm{~m} 2$ para uma área útil de 5217,11m2 (AUC, CUC 2009-163).

A análise dos elementos escritos do projeto aprovado em 1944 faz crer que não houve, da parte de quem concebeu a transformação do edifício, qualquer intenção de correr riscos no planeamento da obra. Além de não se poder omitir o facto de que os preços destas soluções eram convidativos no mercado da altura, também é importante referir que os materiais escolhidos eram de uso comum, já 
tendo dado provas das suas capacidades e qualidades. Naturalmente que este tipo de abordagem conservadora traz grandes benefícios em termos de durabilidade, o que se veio a confirmar.

Ainda que a aprovação do projeto date de meados de 1944, já desde o início do ano que se davam passos importantes no sentido da execução da obra. Em sessão da CAPOCUC de 3 de janeiro, foi aprovada a conveniência da execução das obras da fachada posterior em simultâneo com as obras de construção do Arquivo da Universidade de Coimbra, edifício contíguo à referida fachada e que se encontrava em construção. Nesse sentido, foi enviada uma apresentação ao Ministério das Obras Públicas onde também foi sugerida a dispensa das legalidades formais de maneira a que o contrato da obra da fachada posterior fosse entregue à firma $A$. Maia Lda., que desde 1942 estava responsável pela construção do Arquivo, antes que as obras deste último tomassem "grande desenvolvimento", uma vez que seriam necessárias obras de demolição e construção na fachada posterior da então Faculdade de Letras, com vista à junção física dos dois edifícios. A execução dos trabalhos foi então adjudicada à firma atrás referida pelo valor de $103.907 \$ 00$ (AUC, CUC 2009-163; CUC 2010-267).

Em maio de 1944, seria a vez das obras de transformação das fachadas laterais serem adjudicadas diretamente ao mesmo empreiteiro por $300.000 \$ 00$. Em agosto, começaram os trabalhos. A fachada escolhida para início das obras foi a fachada lateral direita, a poente (AUC, CUC 2010-267).

Em meados de 1945, concluíram-se as obras da fachada posterior, seguida do fim da transformação da fachada lateral direita, em setembro. Mas a 21 de dezembro foi dada a ordem para a interrupção das obras na fachada lateral esquerda, a nascente. A indicação tinha vindo da Faculdade de Letras, que assim considerou evitar o prejuízo dos serviços da Faculdade. É que enquanto o edifício da nova Faculdade de Letras não estivesse pronto (viria a ser inaugurado em 
1951), as aulas e os serviços continuavam a funcionar na Faculdade de Letras de Silva Pinto, o que foi uma das principais causas da demora do processo da transformação em Biblioteca Geral. Foi considerado que a interrupção deveria durar "até ao início das férias grandes" seguintes. A obra seria finalmente concluída em dezembro do mesmo ano (AUC, CUC 2010-267).

Foi preciso esperar até meados de 1950 para haver desenvolvimentos merecedores de referência no processo da transformação da Faculdade de Letras em Biblioteca Geral. Em 2 de maio, foi aprovado, pelo Ministro das Obras Públicas o "projeto de alterações da fachada principal da Biblioteca Central [Biblioteca Geral]". O projeto que nesse dia foi aprovado era na realidade uma segunda versão, uma remodelação da fachada apresentada no projeto geral do edifício de 1944 , vendo agora a austeridade do desenho anterior ser amenizada. A melhor explicação possível do que motivou e se passou nesta alteração é a memória descritiva assinada pelo seu autor, o arquiteto Alberto Pessoa, da qual se retiram os pontos essenciais:

"Tendo sido alterada a Fachada Principal da Faculdade de Letras [...] tornou-se necessário ajustar a Fachada Principal da Biblioteca Central de modo a equilibrá-la com a da Faculdade de Letras [o novo edifício da Faculdade de Letras já estava, nesta altura em fase de conclusão].

Nesta ordem de ideias, foi alterado o perfil das pilastras (agora mais estreitas e salientes) alterando a estereotomia, acertadas as alturas dos vãos e, finalmente, enriquecidos os portões dando-lhes maior volume (altura sobretudo) e enquadrando-os em pórticos de cantaria.

Para maior equilíbrio e ligação da base do edifício condenada a ser cega (salvo os portões) propõe-se a execução de seis baixos-relevos (ou melhor desenhos gravados na pedra com pequenos ressaltos), três de cada lado das entradas" (AUC, CUC 2008-100).

Os baixos-relevos presentes na fachada principal da Biblioteca Geral e os dois grupos escultóricos existentes nos cunhais desta têm 
também um objetivo e representam um papel. Segundo Rosmaninho (2002:729) "o Estado Novo pediu à escultura que enobrecesse o espaço público, que amenizasse as fachadas e que transmitisse um paradigma ideológico. Na Cidade Universitária de Coimbra, ela constitui o toque final na grande composição arquitetónica", afirmando também a "sujeição da escultura à arquitetura".

Biologia, Física, Matemática, Lógica, Gramática e Ética. Estes são os temas representados nos seis baixos-relevos existentes na fachada principal da Biblioteca Geral (aqui ordenados mediante a sua colocação na fachada, da esquerda para a direita). Em conjunto representam a totalidade do saber. Os temas foram escolhidos pelo então diretor da Biblioteca Geral, Lopes de Almeida. Foram encomendados ao escultor Duarte Angélico e a versão final foi esculpida em pedra de Outil, tendo cada relevo $3 \mathrm{~m} 2$. Foram assentados durante o ano de 1951. Já os grupos escultóricos existentes nos dois cunhais da fachada principal foram da autoria do escultor António Duarte em pedra de Lioz. Cada um dos conjuntos contém três figuras para uma altura total de 3,50m. O escultor trabalhou oficialmente nestes grupos escultóricos entre 1944 e 1950, sendo que o seu assentamento foi feito nos primeiros meses de 1951. Sobre o seu significado, nada mais há do que interpretações uma vez que os documentos da CAPOCUC não são indicativos, chegando mesmo a referi-los simplesmente como os "dois grupos escultóricos da Fachada da Biblioteca Geral" (AUC, CAPOCUC 282; CAPOCUC 379).

Apesar de Cottinelli já não estar presente (faleceu em 18 de setembro de 1948), os seus princípios e as suas orientações para a Cidade Universitária de Coimbra mantiveram-se intactos na Fachada Principal da Biblioteca Geral. Apesar de ter sido Pessoa o seu autor, esta fachada faz crer que é da responsabilidade de Cottinelli. Hoje sabe-se que estaria para breve o fim da monumentalidade de Alberto Pessoa e que este, certamente por motivos de força maior, concretizou pela última vez a visão de Cottinelli. O desejo de grandeza e 
de monumentalidade que só a simetria poderia satisfazer está aqui perfeitamente explícito. A fachada principal é o único elemento totalmente politizado de toda a transformação em Biblioteca Geral. Aqui esteve exclusivamente em causa o seu papel no conjunto da Cidade Universitária, na sua monumentalidade e no seu significado. Para Cottinelli seria, muito provavelmente, o único ponto de interesse da transformação. Fator que viria a revelar-se benéfico na conceção do seu interior.

Relativamente à construção da fachada principal, a abertura das propostas a concurso para a execução da obra foi feita em 2 de junho de 1950. A proposta vencedora foi a da firma Sociedade de Construções do Centro Lda. Propôs concluir a obra no prazo previsto de 250 dias por um valor de $685.000 \$ 00$. Sem sobressaltos, a construção da fachada ficou concluída antes de meados de Abril de 1951.

A 23 de junho de 1952, Alberto Pessoa enviou à CAPOCUC o "projeto da Biblioteca Geral revisto e modificado". Este projeto era o fruto das alterações sugeridas ao longo dos últimos seis anos, desde a aprovação do projeto, em 1944. O principal motivo destas alterações foi a intervenção do diretor da Biblioteca Geral, que não hesitava em sugerir modificações quando pensava serem para melhorar o funcionamento da Biblioteca (AUC, CUC 2010-267). Esta revisão do projeto, apesar de contar com as indicações do diretor, já denota a presença e o génio de Alberto Pessoa.

Nesta altura já estava pronto o novo edifício da Faculdade de Letras, no qual as aulas começariam em outubro de 1952. Assim, o trabalho de revisão do projeto era a peça que faltava para se avançar com a última etapa da construção: o interior.

O concurso para a "execução das obras de arranjo interno e cobertura de todo o edifício da Biblioteca Geral" foi publicado em 13 de novembro de 1952, estabelecendo como base de licitação 4.210.000\$00 e um prazo de execução de 540 dias. As propostas foram abertas em 29 de novembro de 1952 e a vencedora foi a da firma A. Maia 
Lda., empresa com sede em Coimbra e que já tinha feito as obras de transformação das fachadas posterior e laterais. Venceu com uma proposta onde apresentava uma solução de substituição da estrutura de Betão Armado por uma de Betão Pré-esforçado. Esta solução permitiu-lhes apresentar a proposta de menor valor: $3.836 .000 \$ 00$ para os 540 dias previstos (AUC, CAPOCUC 334 I).

Em janeiro de 1953 começou a mudança de livros para outros locais, o primeiro passo com vista às extensas obras que se avizinham. Nesse mesmo mês, a obra foi consignada ao empreiteiro. $O$ começo estava para breve (AUC, CAPOCUC 334 I).

O mapa do Plano de trabalhos das "obras de arranjo interno e cobertura de todo o edifício da Biblioteca Geral" ficou completo em julho de 1954, mas as obras continuaram. A consciência de que o prazo para a conclusão das obras não seria cumprido já existia há algum tempo e, por essa razão, a 8 de junho de 1954 tinha sido dada autorização para a que as obras fossem prolongadas até 31 de dezembro do mesmo. Este prazo também não seria cumprido (AUC, CAPOCUC 334 I).

Várias razões são responsáveis pelo atraso no andamento dos trabalhos, das quais se vão referir as mais importantes pela sua complexidade ou pelo maior tempo que demoraram a ser solucionadas. Durante as obras foram feitas inúmeras alterações aos planos e ao projeto inicial motivadas por situações imprevistas surgidas com o começo das demolições, como a instabilidade do existente. Isto fez com que o ritmo das demolições tivesse de abrandar para não pôr em risco a estrutura a conservar. Os imprevistos em obra motivaram ainda um outro tipo de atraso, uma vez que o empreiteiro era o primeiro a deparar-se com as situações, que depois comunicava à CAPOCUC, por quem eram revistas e apresentadas as soluções. Apesar dos registos indicarem que houve sempre uma grande colaboração entre os intervenientes para a resolução deste tipo de situações, os meios de comunicação em 1954 não eram tão rápidos 
como os de hoje e o facto de o poder decisório estar na delegação da CAPOCUC de Lisboa também não ajudava à celeridade do processo. Outras alterações ao projeto inicial foram motivadas por sugestões do diretor da Biblioteca Geral. A mudança da biblioteca de S. Pedro, existente dentro do edifício, foi também motivo de atraso na obra. Em setembro de 1953, o empreiteiro pediu à CAPOCUC que lhes fosse desbloqueada a situação desta biblioteca, sobre a qual o reitor da Universidade de Coimbra tinha deixado indicações expressas para não ser tocada. Só em fevereiro de 1955 se mudaram os livros e as obras foram desbloqueadas (AUC, CAPOCUC 334 I).

As obras de arranjo interno e da cobertura tiveram o seu fim oficial em julho de 1955, mas depois desta data ainda foram feitos alguns acabamentos de menor importância. O custo total da obra era, até agosto de 1956, de 10.721.776\$00 (AUC, CAPOCUC 7A).

A cerimónia oficial de inauguração do edifício da Biblioteca Geral da Universidade de Coimbra decorreu a 29 de maio de 1956, cerimónia partilhada com a inauguração da Faculdade de Medicina. O Estado fez-se representar pelos ministros das Obras Públicas, Eduardo de Arantes e Oliveira, e da Educação, Francisco de Paula Leite Pinto. Em representação da Universidade de Coimbra estiveram o seu reitor, Maximino Correia, e o diretor da Biblioteca Geral, Manuel Lopes de Almeida. Presente na mesa de honra esteve ainda o diretor da Faculdade de Medicina, Augusto Vaz Serra (Discursos, 1956).

Em 19 de março de 1962, a Biblioteca Geral da Universidade de Coimbra foi aberta ao público.

O caso da Biblioteca Geral é diferente de todos os outros edifícios na Alta, podendo mesmo ser considerado um projeto híbrido, já que tantas foram as fontes e as alterações que sofreu. Nasceu como a transformação de um edifício que já havia nascido em cima de alicerces destinados a outro fim.

Durante a década de 1940 podem ser identificados dois campos distintos no desenvolvimento do projeto. No primeiro campo inclui- 
-se a excessiva, ainda que conseguida, preocupação em adaptar as fachadas à monumentalidade pretendida para o espaço exterior do conjunto universitário, onde a fachada principal é o expoente máximo sendo mesmo a única parte do edifício feita de raiz. No segundo campo está o enorme trabalho em adaptar um edifício a funções diferentes das que tinha na época, que por sua vez não eram as mesmas para as quais tinham sido lançadas as bases do mesmo edifício. Era enorme o desafio de fazer cumprir em obra alheia o programa de um edifício que, para todos os efeitos, teria de responder às necessidades como se de um novo se tratasse. Era necessário um edifício que dignificasse uma instituição do valor e importância da Biblioteca Geral da Universidade de Coimbra.

É de notar que a adaptação do interior do edifício foi feita em processos aparentemente autónomos dos que desenvolveram as fachadas, não havendo um estudo conjunto. A única relação direta entre exterior e interior no projeto de adaptação foi o rebaixamento do piso de entrada para o nível da Porta Férrea, feito para regularizar o terreno exterior e com isso aumentar a monumentalidade do conjunto universitário e do seu eixo principal, compreendido entre a Praça de D. Dinis e o Largo da Porta Férrea.

Parece claro que esta "autonomia" foi benéfica para o desenho do interior que assim ficou livre dos rígidos parâmetros monumentais do exterior. De facto, a conceção do interior começou por ser uma simples adaptação do existente às necessidades e funções futuras mas facilmente ultrapassou o meramente aceitável: A distribuição interior, aparentemente labiríntica, é na realidade relativamente simples quando percorrida. A divisão entre espaços de acesso ao público e as áreas técnicas foi muito bem pensada. Todas as áreas públicas são abertas e com boa iluminação natural, estando facilmente acessíveis. A grande Sala de Leitura, acompanhada da sua galeria, é o ponto mais agradável e confortável de todo o edifício. Apesar da sua grande escala é acolhedora, e assim seria suposto 
pois é aqui que os estudiosos passam grandes temporadas. As zonas de armazenamento de livros estão distribuídas em volta da sala de Leitura, o que facilita o acesso e a disponibilização das espécies. A criação de pisos intermédios para depósitos de livros, apesar de não ser original, assentou perfeitamente num edifício cujos limites exteriores estavam definidos à partida.

Mas a análise do edifício não pode ficar pelo óbvio, os 20 anos de processos que o envolvem obrigam a ir mais além. De facto, o longo processo de desenvolvimento do edifício, desde as primeiras intenções de 1936 à sua inauguração em 1956, compreende o espaço temporal no qual se deu a principal mudança no caminho da arquitetura portuguesa do séc. XX: o fim da arquitetura de Estado - e consequente fim do monumental - e o ressurgimento do modernismo. $O$ edifício da Biblioteca Geral faz prova, talvez como nenhum outro, dessa passagem.

O tempo de seguir ideias gastas e parâmetros gerais tinha-se transformado num tempo de ideias novas, fruto da originalidade, do gosto e das vivências de cada um. As obras para servir o Estado foram substituídas por outras concebidas para servir o ser humano.

Foi exatamente isso que se passou no processo da adaptação da Faculdade de Letras em Biblioteca Geral. Um arquiteto subalterno evoluiu para um arquiteto interventivo e de ideias próprias e o início monumental abriu caminho a um final protomodernista.

O modernismo representa mais uma mistura na hibridez do edifício, mas a ligação com as restantes acontece de uma maneira quase perfeita, dando-lhe a simplicidade e a objetividade tão típicas do modernismo, aumentando exponencialmente a qualidade da vivência do edifício. Transforma o interior do edifício num conjunto sereno e unificado. Um conjunto de situações e pormenores que interagem e que se complementam.

Os apontamentos modernistas mostram que a intervenção de Alberto Pessoa na transformação do edifício da Faculdade de Letras 
em Biblioteca Geral foi muito além das competências que inicialmente Ihe foram atribuídas. Conseguiu deixar a sua marca num edifício para o qual deveria apenas adaptar as vontades e necessidades de outros a uma obra que também ela própria era de outro.

No processo de idealização, conceção e construção da Biblioteca Geral, considera-se haver dois pontos fundamentais a reter:

O primeiro é a evidente conotação política e a consequente arquitetura monumental que calculou, controlou e monopolizou todo o espaço envolvente e as fachadas do edifício, tendo como máximo enfoque a monumentalíssima fachada principal voltada para o também monumental Largo da Porta Férrea.

O segundo é a grande vitória de Alberto Pessoa ao conseguir unir uma "manta de retalhos" que já vinha do neoclassicismo do séc. XIX e início do séc. XX, pelo monumentalismo dos anos de 1940 e assistiu ao ressurgimento do modernismo em Portugal. Além disto, há a acrescentar a influência do grande número de pessoas de várias áreas e responsabilidades que intervieram e deixaram a sua ideia no projeto e na execução.

Pessoa juntou tudo e transformou a antiga Faculdade de Letras num edifício digno e eficaz, onde todas as necessidades foram supridas e as foi suprindo durante as décadas seguintes. Criou um edifício detentor de uma simplicidade organizacional marcante, tanto nas zonas de acesso público como nas zonas técnicas (nestas últimas é de salientar o enorme respeito pela escala humana) onde a vivência apela ao regresso do visitante.

\section{Bibliografia}

Inauguração dos Edifícios da Biblioteca Geral e da Faculdade de Medicina construídos pela Comissão de Obras da Cidade Universitária de Coimbra : discursos. Coimbra, 1956. Separata de: Anuário da Universidade de Coimbra, 1955-1956. 
ROSMANINHO, Nuno - O Princípio de uma "revolução urbanística" no Estado Novo : os primeiros programas da Cidade Universitária de Coimbra. Coimbra : Minerva, 1996.

\section{Dissertações e trabalhos académicos}

ROSMANINHO, Nuno - O poder da arte : o Estado Novo e a Cidade Universitária de Coimbra. Coimbra : [s.n.], 2002. Dissertação de Doutoramento em História Contemporânea - versão em CD-ROM.

\section{Documentos manuscritos e dactilografados - Arquivo da}

\section{Universidade de Coimbra}

Processos/ Maços (catálogo - cota - assunto):

CAPOCUC - 7A - Texto e imagem - informação geral.

CAPOCUC - 282 - [edifício BGUC] Baixos-relevos, 1950-1951.

CAPOCUC - 334 I e II - [edifício BGUC] Empreitada de arranjo externo e cobertura, 1952-1955.

CAPOCUC - 379 - Faculdade de Medicina: obras de arte.

CUC 2008 - 100 - [edifício BGUC] Projeto nova fachada principal, 1950.

CUC 2009 - 163 - [edifício BGUC] Projeto - texto, 1944.

CUC 2010 - 267 - [edifício BGUC] Biblioteca Central (fachadas), 1942-1955. 